\title{
PREVISÃO DA QUALIDADE DO AR ATRAVÉS DO SOFTWARE CAL3QHC
}

\author{
A. F. X. RAMOS, I. Q. MARINHO, V. V. MURATA \\ Universidade Federal de Uberlândia, Faculdade de Engenharia Química \\ e-mail para contato: valeria@ufu.br
}

RESUMO - A qualidade do meio ambiente e a saúde da população são afetadas pelos altos niveis de poluição encontrados nos centros urbanos. Este trabalho utiliza o software livre CAL3QHC para prever a concentração de poluentes em uma via com grande fluxo de veículos e de pessoas na cidade de Uberlândia (MG). O modelo matemático considera o efeito das variáveis atmosféricas como direção e velocidade do vento e as características do terreno considerado. O estudo utiliza os dados apresentados em Fernandes (2014) para caracterização da frota e identificação dos links de fila e links livres e para a localização dos receptores. Os resultados obtidos de concentração de poluentes em cada receptor para diferentes ângulos são coerentes com o observado experimentalmente.

\section{INTRODUÇÃO}

$\mathrm{O}$ advento das tecnologias nos setores agrícola e industrial observado nos últimos anos vem causando uma mudança significativa no equilíbrio ambiental. As principais fontes de poluição ambiental decorrentes das ações antropogênicas são as emissões industriais e automotivas nos espaços urbanos, que alteram qualitativa e quantitativamente as características físico-químicas dos sistemas atmosféricos.

O incremento constante da frota veicular movida por combustíveis tem levado ao lançamento de toneladas de gases e partículas provenientes da exaustão dos motores de combustão na atmosfera, contribuindo com o empobrecimento da qualidade do ar. A poluição do ar por material particulado em suspensão merece destaque devido a sua extensa faixa de tamanhos e a complexidade de sua composição, que pode sofrer variações em função das características da fonte e acarretar problemas no sistema respiratório.

A utilização de modelos matemáticos para a predição da qualidade do ar, associada à crescente capacidade de predição e de medição de condições meteorológicas como velocidade dos ventos, temperaturas, índice pluviométrico e umidade relativa, que afetam diretamente tais condições, constituem-se em ferramentas poderosas para avaliar a eficiência de técnicas de acompanhamento e de remediação da poluição e para traçar políticas globais voltadas para a garantia da qualidade do ar e da minimização dos efeitos nocivos da poluição.

Na cidade de Uberlândia (MG), o monitoramento da qualidade do ar é feito através da medição da concentração de material particulado no Terminal Central. Este tema foi tratado por Silva (2007), Lira (2009) e Fernandes (2013). Silva (2007) desenvolveu modelos matemáticos empíricos de previsão da concentração de partículas totais e de partículas 
inaláveis utilizando regressão linear múltipla. Lira (2009) utilizou modelos baseados em redes neurais e modelos lineares como ARX, ARMAX e Box-Jenkins para a previsão da concentração de partículas inaláveis. Fernandes (2013) avaliou o modelo de dispersão gaussiana utilizado pelo simulador CAL3QHC para tal previsão, associando a este estudo a influência de variáveis meteorológicas no mesmo período e variáveis de tráfegos e estudos da condição da frota na cidade de Uberlândia. Para a avaliação da capacidade de predição deste modelo de pluma, foi utilizada a base de dados do grupo de Sistemas Particulados da Faculdade de Engenharia Química (FEQUI) da Universidade Federal de Uberlândia, tratada estatisticamente, além de parâmetros estabelecidos por órgãos de regulação como o Conselho Nacional do Meio Ambiente através de resoluções específicas.

\section{Descrição do software CAL3QHC}

Os principais modelos disponíveis para a simulação da dispersão de gases e de material particulado na atmosfera são: CAL3QHC, CALPUFF, AERMOD, BLP, OCD, ADAM, AFTOX, HYROAD (http://www.epa.gov/scram001/dispersion_prefrec.htm, acessado em 03/10/13), (http://www.epa.gov/ttn/scram/dispersion_prefrec.htm\#aermod, acessado em 03/10/2013).

Cada um deles adota hipóteses simplificadoras, condições de contorno, grau de detalhamento e métodos de solução específicos e são aplicáveis a cenários específicos, pois são extremamente variáveis e de difícil previsibilidade. Outros aspectos ligados à legislação brasileira sobre o assunto devem ser considerados, pois ao definirem parâmetros de qualidade do ar considerados aceitáveis, tem papel direto sobre a forma como os vários agentes tratarão o assunto.

Para fins de avaliação da dispersão de poluentes atmosféricos em uma via com interseções, semáforos, cruzamentos e com alta circulação de veículos e de pessoas, localizada em Uberlândia (MG), foi escolhido o CAL3QHC (California Line Source for Queuing and Hot Spot Calculations), cujos parâmetros e dados de entrada incluem desde variáveis meteorológicas até condições de tráfego, sincronização de sinais, cruzamento de vias, fluxo de veículos, idade e tipo de frota, topografia do terreno.

O modelo CAL3QHC se baseia no modelo de dispersão de pluma gaussiana. Este é um modelo de dispersão de fonte linear que faz a estimativa da concentração de partículas originadas da combustão nos motores dos veículos. O modelo estima a concentração com veículos em movimento e parados em semáforos.

Os parâmetros de entrada do CAL3QHC devem considerar além do fluxo, tipo e idade da frota, as regulamentações estabelecidas por órgãos como o DENATRAN (Departamento Nacional de Trânsito), DETRAN-MG (Departamento Estadual de Trânsito de Minas Gerais) e SETTRAN (Secretaria Municipal de Trânsito e Transportes de Uberlândia) (Fernandes, 2013).

A entrada de dados é feita através de arquivos, que devem conter as informações necessárias para a execução. A Tabela 1 apresenta um arquivo de entrada padrão com o nome e a descrição do parâmetro e respectiva unidade. 
Tabela 1 - Arquivo de entrada padrão

\begin{tabular}{|c|c|c|c|}
\hline & Nome & Descrição & Unidade \\
\hline \multirow{8}{*}{$\underset{1}{2}$} & JOB & Nome do trabalho & \\
\hline & ATIM & Tempo médio & $\min$ \\
\hline & $\mathrm{ZO}$ & Rugosidade da superfície & $\mathrm{cm}$ \\
\hline & $\mathrm{VS}$ & Velocidade de sedimentação & $\mathrm{cm} / \mathrm{s}$ \\
\hline & VD & Velocidade de deposição & $\mathrm{cm} / \mathrm{s}$ \\
\hline & NR & Número de receptores & \\
\hline & SCAL & Fator de conversão de escala & pés $-0,3048$, metros $-1,0$ \\
\hline & IOPT & Variável binária de escolha de outputs & \\
\hline \multirow{4}{*}{$\underset{\frac{1}{Z}}{2}$} & $\mathrm{RCP}$ & Nome do receptor & - \\
\hline & XR & Coordenada $\mathrm{x}$ do receptor & $\mathrm{m}$ \\
\hline & YR & Coordenada y do receptor & $\mathrm{m}$ \\
\hline & ZR & Coordenada $\mathrm{z}$ do receptor & $\mathrm{m}$ \\
\hline \multirow{4}{*}{$\sum_{3}^{\infty}$} & RUN & Nome & \\
\hline & NM & Número de links & \\
\hline & PRINT2 & Para imprimir o output (1 -sim, 0 - não) & \\
\hline & MODE & $\begin{array}{l}\text { Escolha do material a ser analisado (C - monóxido de } \\
\text { carbono, P - material particulado) }\end{array}$ & \\
\hline$\underset{\square}{\square}$ & IQ & $\begin{array}{l}\text { Escolha do tipo de interseção estudada. } \\
\text { Se for de trânsito livre, digita-se } 1 \text {. Caso seja uma } \\
\text { interseção sinalizada(fila), digita-se } 2 \text {. } \\
\text { Em caso de um link livre, deve-se ir para a linha } 5 \text { c, e } \\
\text { em fila para as linhas } 5 \text { a e } 5 \text { b. }\end{array}$ & \\
\hline \multirow{9}{*}{$\frac{\mathbb{1}}{3}$} & LNK & Nome do link & - \\
\hline & TYPE & $\begin{array}{l}\text { Tipo do link. Podem se classificar em AG(at grade), } \\
\text { FL(at fill), BR(bridge) e DP(depressed) }\end{array}$ & - \\
\hline & XL1 & Coordenada $\mathrm{x}$ do final do link 1 & $\mathrm{~m}$ \\
\hline & YL1 & Coordenada y do final do link 1 & $\mathrm{~m}$ \\
\hline & XL2 & Coordenada $\mathrm{x}$ do final do link 2 & $\mathrm{~m}$ \\
\hline & YL2 & Coordenada y do final do link 2 & $\mathrm{~m}$ \\
\hline & HL & Altura da fonte emissora & $\mathrm{m}$ \\
\hline & WL & Comprimento da zona de mistura & $\mathrm{m}$ \\
\hline & NLANES & Número de faixas de trânsito na interseção & - \\
\hline \multirow{8}{*}{ 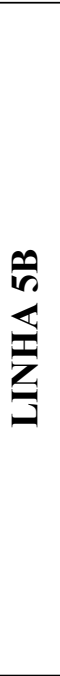 } & CAVG & Tempo médio do ciclo do sinal & $\mathrm{s}$ \\
\hline & RAVG & Tempo médio do ciclo do sinal em fase vermelha & $\mathrm{s}$ \\
\hline & YFAC & $\begin{array}{l}\text { Tempo médio do ciclo do sinal perdido na fase } \\
\text { amarela }\end{array}$ & $\mathrm{s}$ \\
\hline & IV & Fluxo veicular & veículos/hora \\
\hline & IDLFAC & Taxa de emissão de poluentes & g/veículo*hora \\
\hline & SFR & $\begin{array}{l}\text { Taxa de acúmulo de veículos. Para utilizar o valor } \\
\text { padrão deve-se digitar } 1600 \text {. }\end{array}$ & veículo/hora*faixa \\
\hline & ST & $\begin{array}{l}\text { Tipo de sinalização. Deve-se entrar com } 1 \text { para } \\
\text { programado(valor padrão), } 2 \text { para acionado } \\
\text { manualmente e } 3 \text { para semi-acionado. }\end{array}$ & - \\
\hline & AT & $\begin{array}{l}\text { Condição de chegada dos veículos. Digita-se } 1 \text { para a } \\
\text { melhor progressão, } 2 \text { para progressão abaixo da } \\
\text { média, } 3 \text { para progressão média(valor padrão), } 4 \text { para } \\
\text { acima da média e } 5 \text { para a melhor progressão. }\end{array}$ & - \\
\hline
\end{tabular}


Tabela 1 - Arquivo de entrada padrão - continuação

\begin{tabular}{|c|c|c|c|}
\hline & Nome & Descrição & Unidade \\
\hline \multirow{10}{*}{ 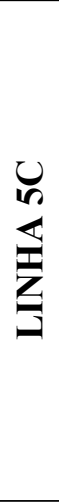 } & LNK & Nome do link & - \\
\hline & TYPE & $\begin{array}{l}\text { Tipo do link. Podem se classificar em AG(at } \\
\text { grade), FL(at fill), BR(bridge) e DP(depressed) }\end{array}$ & - \\
\hline & XL1 & Coordenada $\mathrm{x}$ do final do link 1 & $\mathrm{~m}$ \\
\hline & YL1 & Coordenada y do final do link 1 & $\mathrm{~m}$ \\
\hline & XL2 & Coordenada $\mathrm{x}$ do final do link 2 & $\mathrm{~m}$ \\
\hline & YL2 & Coordenada y do final do link 2 & $\mathrm{~m}$ \\
\hline & VPHL & Fluxo de veículos & veículos/hora \\
\hline & EFL & Taxa de emissão de poluentes & g/veículo*hora \\
\hline & $\mathrm{HL}$ & Altura da fonte emissora & $\mathrm{m}$ \\
\hline & WL & Comprimento da zona de mistura & $\mathrm{m}$ \\
\hline \multirow{10}{*}{ 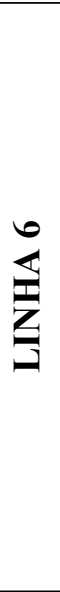 } & $\mathrm{U}$ & Velocidade do vento & $\mathrm{m} / \mathrm{s}$ \\
\hline & BRG & Direção do vento & - \\
\hline & CLAS & Classe de estabilidade atmosférica & - \\
\hline & MIXH & Altura de mistura & $\mathrm{m}$ \\
\hline & AMB & Concentração no ambiente do material estudado & ppm \\
\hline & VAR & $\begin{array}{l}\text { Deve-se entrar com N se somente uma direção } \\
\text { do vento será considerada e Y se houver } \\
\text { variação na direção do mesmo ou variação no } \\
\text { fluxo de dados }\end{array}$ & - \\
\hline & DEGR & Acréscimo ao ângulo na direção do vento & Graus \\
\hline & EFL & Taxa de emissão de poluentes & g/veículo*hora \\
\hline & $\mathrm{VAI}(1)$ & Limite inferior do intervalo de variação & Graus \\
\hline & $\operatorname{VAI}(2)$ & Limite superior do intervalo de variação & Graus \\
\hline
\end{tabular}

\section{Estudo de caso}

Um estudo foi feito realizando simulações com o software CAL3QHC na interseção das Avenidas João Naves de Ávila e João Pinheiro, conforme mostra a Figura 1a. Nessa interseção se localiza o Terminal Central Municipal, por onde passa toda a frota de veículos de transporte de passageiros da rede pública. Além disso, por estar situado na região central da cidade de Uberlândia, apresenta um grande fluxo de pessoas e de veículos particulares.

A Figura $1 b$ apresenta a localização de receptores individuais com espaçamento de 20 metros, totalizando uma área de $14.400 \mathrm{~m}^{2}$. As coordenadas dos 50 receptores foram definidas a partir do centro da interseção, onde é localizada a origem do sistema de coordenadas. 
Figura 1 - Interseção das avenidas João Naves de Ávila e João Pinheiro e localização dos receptores
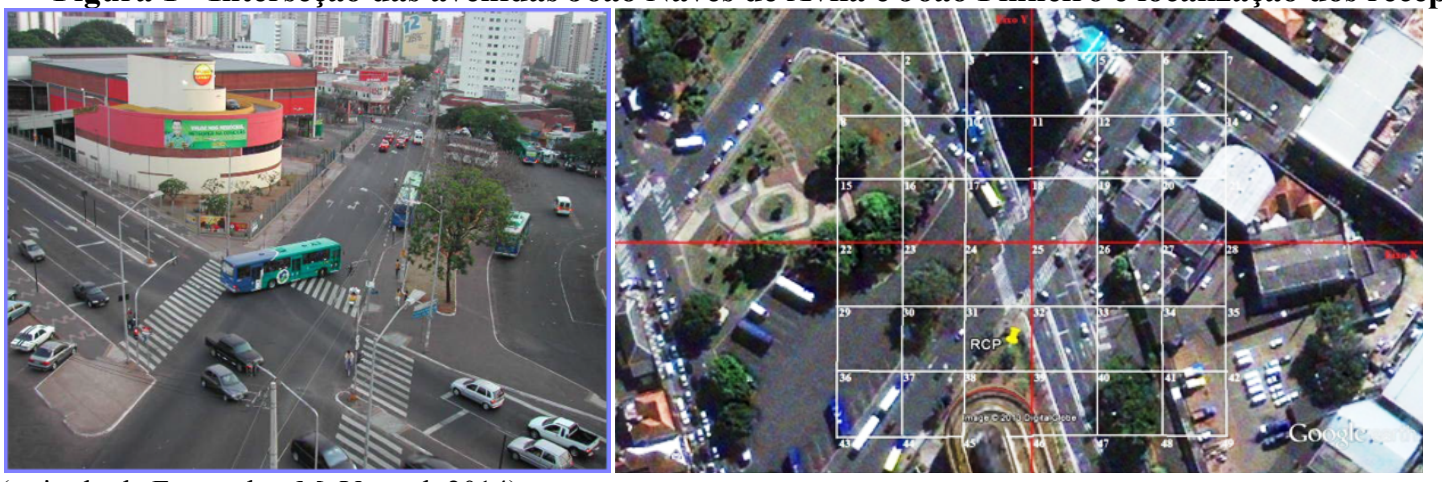

(retirado de Fernandes, M. V. et al, 2014)

Esse estudo de caso utiliza os dados apresentados por Fernandes (2014).

Foram utilizados 14 links de determinação do tamanho da fila de veículos parados nos cruzamentos. Para cada link, foram definidas as coordenadas que identificam suas posições e seus comprimentos. A velocidade do vento considerada foi de $3 \mathrm{~m} / \mathrm{s}$ e a classe de estabilidade atmosférica do tipo D. Na caracterização do terreno, foi considerada uma rugosidade da superfície de $175 \mathrm{~cm}$ e a altura de mistura de $1000 \mathrm{~m}$.

A Figura 2 apresenta um arquivo típico de saída do CAL3QHC, onde são apresentados os valores de concentração de poluentes em cada um dos receptores localizados em diferentes pontos da interseção a uma altura de $1,80 \mathrm{~m}$, para direções do vento variando entre $0^{\circ}$ e $360^{\circ}$.

Figura 2 - Arquivo de saída típico do CAL3QHC

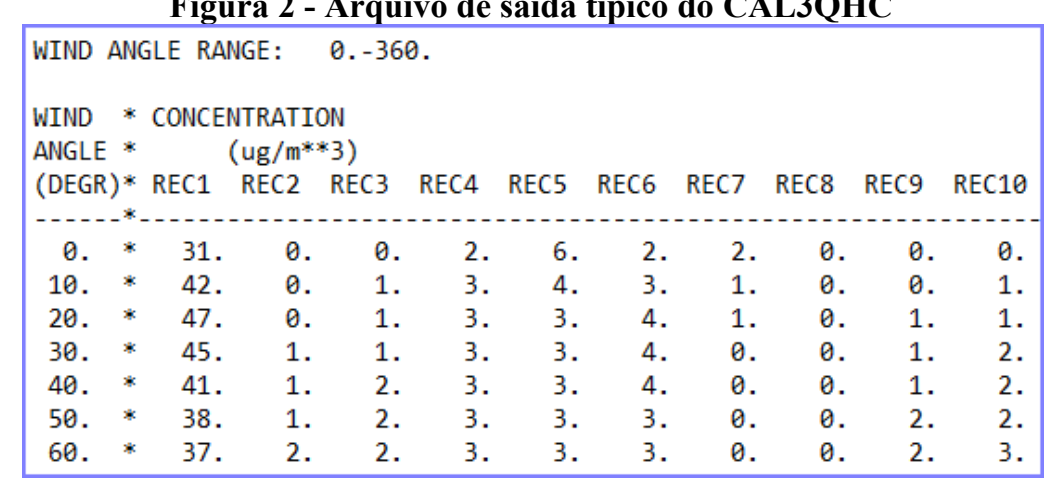

No Gráfico 1 é possível observar as concentrações máximas em cada receptor, nos receptores REC1 a REC10, em diferentes ângulos, que também são gerados pelo código.

Figura 3 - Concentrações máximas de poluentes nos receptores 1 a 10

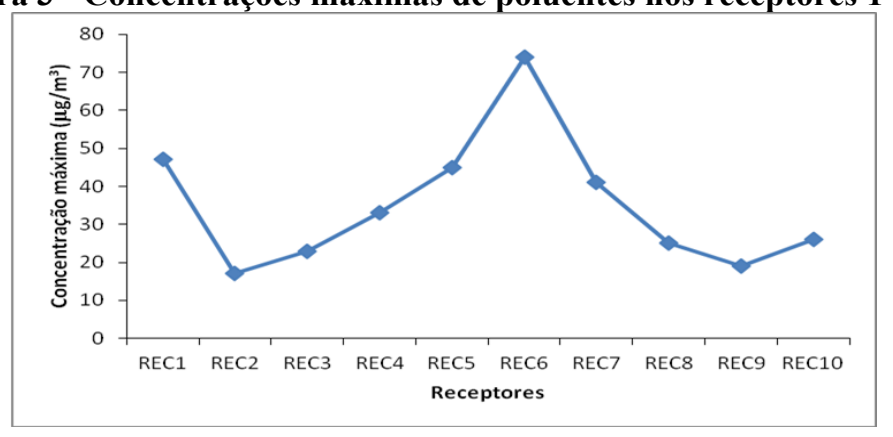


A máxima concentração de poluentes foi observada no receptor 6 , localizado próximo à via de tráfego e, portanto sujeito à poluição oriunda das emissões dos veículos parados nas filas.

\section{Conclusão}

Nos testes feitos foi observado que a concentração aumentava consideravelmente quando fluxo de veículos ou fator de emissão veicular aumentava, sobretudo nos casos em que o ângulo do vento era razoavelmente pequeno. $O$ aumento da velocidade do vento resultava em uma menor concentração de poluentes. Este resultado justifica-se pelo papel dispersor que o vento desempenha.

Devido à grande quantidade de fatores levados em consideração pelo software, como natureza da sinalização, tipos das vias, fluxo de veículos e velocidade do vento, o mesmo apresenta resultados satisfatórios e que podem ser usados para análise de como cada característica afeta na dispersão dos poluentes.

\section{REFERÊNCIAS}

FERNANDES, M.V.O., Simulação da Dispersão de Material Particulado de Origem Veicular, Dissertação (Mestrado) - Faculdade de Engenharia Química, Universidade Federal de Uberlândia, Uberlândia, 2013.

FERNANDES, M.V.O., LIMA, E. A. P., MURATA, V.V., BARROZO, M. A. S., Análise experimental e de simulação da qualidade do ar da cidade de Uberlândia-MG in Tópicos em tratamentos de resíduos e meio ambiente, eISBN 978-85-913116-0-6, Editora Animeris, 364 p., 2014.

LIMA, E. A. P. Um estudo sobre a qualidade do ar de Uberlândia: material em suspensão. 2007. 148f. Tese (Doutorado) - Faculdade de Engenharia Universidade Federal de Uberlândia, Uberlândia, 2007.

LIRA, R. S. Modelagem e previsão da qualidade do ar na cidade de Uberlândia - MG. 2009. 152f. Tese (Doutorado) - Faculdade de Engenharia Química, Universidade Federal de Uberlândia, Uberlândia, 2009.

SILVA, M. G. D. Análise da qualidade do ar com base no fluxo de veículos e variáveis climáticas: o caso da cidade de Uberlândia - MG. 2007. 107 f. Dissertação (Mestrado) -Faculdade de Engenharia Civil, Universidade Federal de Uberlândia, Uberlândia, 2007.

UNITED STATES ENVIRONMENTAL PROTECTION AGENCY. User's Guide to CAL3QHC Version 2.0: a modeling methodology for predicting pollutant concentrations near roadway intersections. EPA-454/R-92-006, U.S. EPA: Office of Air Quality Planning and Standards, Research Triangle Park, North Carolina, 1995. $115 p$. 